\title{
Feminicídios em municípios de fronteira no Brasil
}

\author{
Femicide in borderline Brazilian municipalities
}

Stela Nazareth Meneghel (https://orcid.org/0000-0002-7219-7178) ${ }^{1}$

Ian Meneghel Danilevicz (https://orcid.org/0000-0003-4541-0524) ${ }^{2}$

Mauricio Polidoro (https://orcid.org/0000-0002-7278-0718) ${ }^{3}$

Luiza Maria Plentz (https://orcid.org/0000-0001-8647-7923) ${ }^{4}$

Bruna Pereira Meneghetti (https://orcid.org/0000-0002-7695-6987) ${ }^{5}$

${ }^{1}$ Escola de Enfermagem

- Saúde Coletiva,

Universidade Federal do

Rio Grande do Sul. R. São

Manoel 963, Rio Branco.

90620-110 Porto Alegre RS

Brasil.

stelameneghel@gmail.com

${ }^{2}$ CentraleSupelec - Doctorat

Mathématiques Appliquées,

Université Paris-Saclay.

Île-de-France France.

${ }^{3}$ Instituto Federal de

Educação Ciência e

Tecnologia do Rio Grande

do Sul. Porto Alegre RS

Brasil.

${ }^{4}$ Departamento de Saúde

Coletiva, Universidade

Federal do Paraná. Curitiba

PR Brasil.

${ }^{5}$ Escola de Enfermagem,

Universidade Federal do Rio

Grande do Sul. Porto Alegre

RS Brasil.

\begin{abstract}
This quantitative study analyzed female deaths due to agression in the 122 municipalities that are part of the Brazilian borderline. Borders are territories of conquest, conflict and violence and Brazilian border cities have high rates of male and female homicides. This study aimed to quantify female deaths from agression in border towns and identify factors associated with these deaths. Female deaths from agression are considered an indirect indicator of femicides and were the outcome of a multivariate analysis using the Poisson model. In the 2000-2015 period, 1,384 women died from agression, which represent a mean rate of 5.8/100,000 women; of these, 181 were in indigenous women (13\%). We observed the pattern of distribution of these deaths, which occurred predominantly in the Central Arch, larger municipalities, and where there are more migrants. There is heterogeneity in the rates of violence in the municipalities that are part of the borderline, indicating a close look at the most populous places, with a high presence of migration and female deaths due to agression. However, we should also pay attention to the small municipalities where there has been a change in pattern, with an abrupt increase in the number of female murders.
\end{abstract}

Key words Feminicides, Borders, Violence, Women violence
Resumo Estudo quantitativo que analisou as mortes de mulheres por agressão nos 122 municípios que fazem parte da linha de fronteira brasileira. As fronteiras são territórios de conquista, conflito e violência, e nos municípios de fronteira brasileiros há taxas elevadas de homicídios masculinos e femininos. O objetivo do estudo foi quantificar as mortes femininas por agressão nesses municípios e identificar fatores a elas associados. As mortes femininas por agressão, consideradas um indicador indireto dos feminicídios, foram o desfecho de uma análise multivariada utilizando o modelo de Poisson. No período de 2000 a 2015, ocorreram 1.384 mortes de mulheres por agressão, representando uma taxa média de 5,8/100.000 mulheres; dessas, 181 eram indígenas (13\%). Observou-se o padrão de distribuição desses óbitos, que aconteceram predominantemente no Arco Central, em municípios maiores e onde há mais migrantes. Há uma heterogeneidade nas taxas de violência nos municípios que fazem parte da linha de fronteira, indicando um olhar atento aos locais mais populosos, com alta presença de migração e taxas elevadas de mortes femininas por agressão. Mas também se recomenda atentar para municípios pequenos em que houve mudança de padrão, com elevação abrupta no número de assassinatos de mulheres.

Palavras-chave Feminicídios, Fronteiras, Violências, Violência contra a mulher 


\section{Introdução}

As fronteiras constituem lócus de relações de produção, fluxos humanos, trocas materiais e simbólicas, conflitos transculturais e identitários. Revelam as interações entre o homem, a terra e a natureza, em um ordenamento territorial cuja síntese envolve as dimensões política, econômica, simbólica e cultural ${ }^{1}$.

A fronteira é um fenômeno não somente espacial e histórico, mas uma confrontação cultural, ideológica e econômica em que diferentes sujeitos são constituídos em sua diversidade étnica, racial e cultural. Estabelece uma linha de contato entre diferentes tipos de assentamento e de usos do espaço, encontro de territorialidades e lócus onde se agudizam as contradições e as violências.

As dimensões etnocêntricas, racistas e patriarcais produzidas historicamente no bojo do colonialismo, acompanham a fronteira de modo que esse espaço constitui um cenário de conquista, de instabilidade e de violência. Para Martins ${ }^{2}$, a fronteira no Brasil se caracteriza sobretudo pelo conflito social, em que o movimento de expansão territorial do capital sobre territórios indígenas e populações camponesas resultou em massacres, especialmente de mulheres e crianças, e na subordinação dos trabalhadores. Nessas zonas de contato, destaca-se a forma cruel com que os ditos "civilizados" ou os donos de terra subjugam outros seres humanos, por meio da escravidão, inclusive a sexual, da servidão e da morte ${ }^{3}$.

As regiões de fronteira de vários países da América do Sul e Central estão envolvidas com os tráficos, que podem ser de drogas, de mercadorias e de pessoas ${ }^{4}$, e embora as situações de violência contra a mulher não sejam específicas desses territórios, elas são agravadas pela histórica presença ambígua do Estado nesses locais. Tal ambiguidade é uma constituinte importante dos estados de periferia ${ }^{5}$ posicionados subalternamente na divisão internacional racializada e generificada do trabalho, que possuem nas fronteiras um lócus de sustentação do capitalismo global mantido por dominação, exploração e violência ${ }^{6,7}$.

Nesses cenários de fronteira, ocorrem os mais variados tipos de tráficos: de armas, de drogas e de pessoas. O de pessoas é marcado por um viés de gênero, que visa a exploração sexual, a prostituição forçada, o trabalho degradante ou escravo em contextos nos quais as vítimas, em sua maioria, são mulheres, crianças, adolescentes, transexuais, pobres, camponesas ${ }^{8}$ e pessoas com baixa escolaridade em ocupações precárias ${ }^{9-12}$. Essas condições representam um risco de violência letal, sobretudo para as mulheres, o que constitui um feminicídio, entendido como a morte de mulheres devido ao fato de serem mulheres ${ }^{13}$. Em termos geográficos, as américas do Sul e Central e o Caribe constituem locais de alta prevalência de feminicídios, e entre os 25 países que apresentam as taxas mais elevadas, 14 estão nessa região, com o Brasil ocupando a quinta posição em números absolutos $^{14}$.

No Brasil há 588 municípios na faixa de fronteira (situados a até $150 \mathrm{~km}$ da divisa) e 122 limítrofes, ou seja, localizados na linha de fronteira. Está documentada a alta frequência de homicídios nessas regiões ${ }^{15}$, principalmente nos municípios mais populosos ${ }^{16}$. No período de 2000 a 2010, dos 20 municípios mais violentos do país, quatro eram de fronteira ${ }^{17}$, o que indica a banalidade da violência nessas regiões.

Fatores que aumentam os feminicídios estão associados à cultura patriarcal, ao culto de uma virilidade agressiva e machista e ao padrão de resolução de conflitos violento e privado ${ }^{18}$. Os feminicídios, assim como os homicídios masculinos, são territorialmente concentrados, e observou-se que as mortes femininas por agressão são maiores em locais em que as mortes masculinas também são elevadas, onde há conflitos associados ao tráfico, grilagem de terras e violência estrutural ${ }^{19,20}$.

O objetivo deste estudo foi quantificar os feminicídios em municípios na linha de fronteira do Brasil em uma série histórica e identificar fatores associados. Secundariamente, buscou-se identificar eventos singulares que poderiam estar ocorrendo em alguns territórios e vulnerabilizando populações específicas.

\section{Método}

Trata-se de um estudo quantitativo que analisou a mortalidade feminina por agressão nos 122 municípios que fazem parte da linha de fronteira brasileira. A base territorial para a fronteira brasileira inclui a divisão em três arcos. O Arco Norte compreende municípios pertencentes ao Amapá, Pará, Amazonas, Roraima e Acre; o Arco Central inclui Rondônia, Mato Grosso e Mato Grosso do Sul; e o Arco Sul abrange Paraná, Santa Catarina e Rio Grande do Sul ${ }^{21}$.

As mortes femininas por agressão foram obtidas por meio dos dados das declarações de óbito de mulheres residentes nos 122 municípios brasileiros de fronteira procedentes do Sistema 
de Informação de Mortalidade (SIM) do Departamento de Informática do Sistema Único de Saúde (DATASUS) do Ministério da Saúde para o período 2000 a 2015, organizando uma série histórica para observar a tendência do evento nos municípios. Os óbitos corresponderam ao intervalo X85 a Y09 da décima edição da Classificação Internacional de Doenças (CID-BR10). Os municípios foram estratificados segundo o arco (Norte, Centro e Sul) e de acordo com o tamanho da população (menores e maiores de $20 \mathrm{mil}$ habitantes). Nem todas as mortes femininas por agressão decorrem de condições de gênero mas, como em outros estudos ${ }^{22}$, serão consideradas em sua totalidade, como um proxy ou um indicador indireto do feminicídio.

Foram selecionadas variáveis independentes que poderiam estar relacionadas a essas mortes: migração (número de migrantes total e de mulheres segundo os dados do Instituto Brasileiro de Geografia e Estatística - IBGE para os anos de 2000 e 2010); concentração de renda (índice de Gini - IBGE, 2000 e 2010); raça/cor (percentual de população autorreferida como negra - IBGE, 2000 e 2010); população (menor e maior de 20 mil habitantes - IBGE, 2000 e 2010), percentual de evangélicos pentecostais (IBGE, 2010) e violência sexual (percentual de notificações em mulheres, segundo os dados do Sistema de Informação de Agravos de Notificação - SINAN para o período de 2009 a 2015). Para as variáveis que só possuíam valores para os anos censitários, realizou-se interpolação dos dados para os anos intermediários, distribuindo proporcionalmente o incremento observado no último ano. A variável dependente foi a taxa de mortes femininas por agressão para o período.

Incluiu-se no modelo apenas o percentual de evangélicos pentecostais, excluindo outras religiões, que apresentaram colinearidade. Além disso, a informação sobre violência sexual em mulheres não foi inserida no modelo devido ao excesso de dados ignorados, já que a notificação obrigatória das violências no Brasil, disponível no SINAN, começou em 2009. O mesmo ocorreu com as mortes de mulheres indígenas para as quais se analisaram apenas os aspectos descritivos, pelo fato de se encontrarem concentradas em poucos municípios.

A regressão de Poisson, um modelo linear generalizado, foi usada para a análise ${ }^{23}$. O modelo foi testado com as diferentes variáveis, optando-se pelo que apresentou melhor desempenho (AIC 3066). A elaboração cartográfica dos resultados foi realizada no software ArcGIS 10.3, com a licença da Universidade Federal do Rio Grande do Sul.

Este artigo faz parte da pesquisa "Femicídios e assassinatos pautados em gênero no Rio Grande do Sul", aprovada no CEP/ESP.

\section{Resultados}

De 2000 a 2015, foram notificados, nos $122 \mathrm{mu}$ nicípios brasileiros de fronteira, 1.384 óbitos femininos por agressão, representando uma taxa média de 5,8/100 mil mulheres, superior à média nacional, de 4,8, em $2015^{22}$. Nos municípios da linha da fronteira, ao longo da série histórica, ocorreu um aumento paulatino nas frequências de mortes por agressão, na proporção de $0,9 \mathrm{ca}$ sos/ano.

Nesse período, ocorreram 12.806 homicídios masculinos, representando uma razão de 17,7 mortes masculinas para cada morte feminina. A população dos municípios da linha de fronteira representa $1,5 \%$ da população brasileira, os óbitos masculinos constituem 1,7\% do total de homicídios masculinos, e os femininos, 2,1\% do total de homicídios de mulheres no país.

$\mathrm{Na}$ linha de fronteira, 83 municípios possuíam população menor do que 20 mil habitantes, e neles ocorreram 258 óbitos, enquanto nos 39 municípios com mais de 20 mil habitantes foram notificados 1.076. Entre os municípios com população menor do que 20 mil habitantes, a distribuição dos óbitos é compatível com a de eventos raros, sendo que em 22 municípios não houve notificação de óbitos e 26 notificaram até cinco óbitos dispersos ao longo dos 16 anos de estudo.

O Quadro 1 apresenta as médias e os desvios padrão referentes às variáveis do estudo. O Arco Central apresentou as maiores taxas de mortes femininas por agressão (8,56/100 mil mulheres) e os maiores contingentes de migrantes e de notificações de violência sexual. Os municípios do Arco Norte apresentaram taxa de 5,54 mortes/100 mil mulheres, os maiores percentuais de evangélicos pentecostais, de população negra e a maior concentração de renda. No Arco Sul houve menor concentração de renda, taxas menores de feminicídio $(2,41 / 100 \mathrm{mil})$ e de notificações de violência sexual.

Em relação ao local, não houve diferença significativa entre as mortes segundo o local de ocorrência ou residência, optando-se então por utilizar o segundo indicador.

A Figura 1 mostra as frequências e taxas de feminicídios nos 122 municípios fronteiriços 
Quadro 1. Média e desvio padrão de mortes femininas por agressão e variáveis independentes, 2000-2015.

\begin{tabular}{|l|r|r|r|r|r|r|}
\hline & Arco Norte & \multicolumn{1}{c|}{ DP } & Arco Central & \multicolumn{1}{c|}{ DP } & Arco Sul & DP \\
\hline Migração 2010 (n) & 2451,3 & 2806,1 & 3234,3 & 3401,8 & 946,5 & 888,7 \\
\hline População negra 2000 (\%) & 60,9 & 12,0 & 45,5 & 10,9 & 12,5 & 5,9 \\
\hline População negra 2010 (\%) & 61,6 & 13,5 & 51,6 & 11,4 & 18,4 & 7,4 \\
\hline Pentecostais 2000 (\%) & 15,6 & 7,6 & 12,0 & 3,6 & 7,8 & 4,1 \\
\hline Pentecostais 2010 (\%) & 17,1 & 5,5 & 13,9 & 2,6 & 8,7 & 4,4 \\
\hline Índice de Gini 2000 & 0,62 & 0,06 & 0,59 & 0,05 & 0,56 & 0,05 \\
\hline Índice de Gini 2010 & 0,63 & 0,07 & 0,57 & 0,04 & 0,51 & 0,05 \\
\hline Violência sexual (\%) & 4,1 & 5,3 & 6,9 & 9,9 & 1,4 & 1,8 \\
\hline Feminicídios residência (médias) & 0,82 & 1,17 & 1,76 & 2,06 & 0,28 & 0,46 \\
\hline Feminicídios ocorrência (médias) & 0,83 & 1,21 & 1,80 & 2,16 & 0,27 & 0,45 \\
\hline Taxa feminicídios & 5,49 & 14,60 & 8,56 & 12,22 & 2,41 & 8,46 \\
\hline
\end{tabular}

Fonte: IBGE, 2000, 2010; Brasil, Ministério da Saúde. DATASUS, 2000-2015.

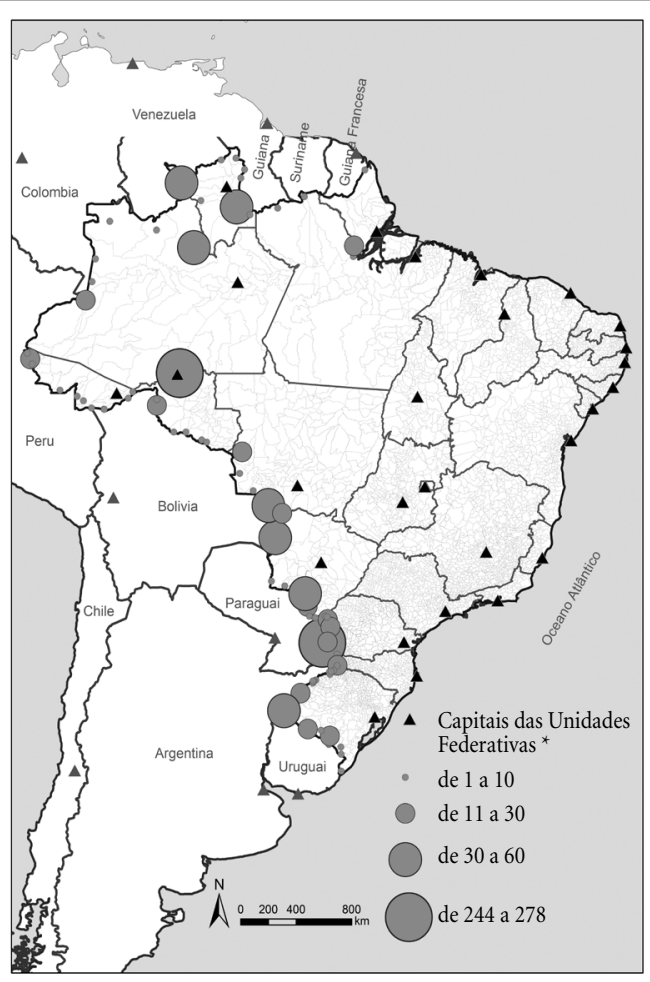

(total de feminicídios, por município da ocorrência (2000-2015)

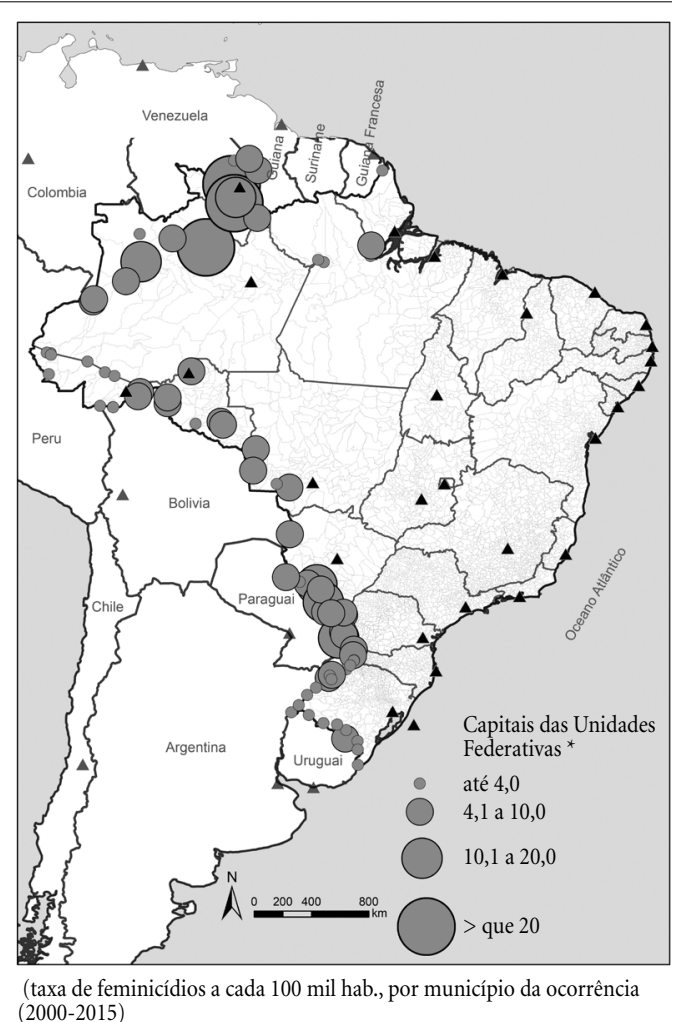

$(2000-2015)$

Figura 1. Número de casos (A) e taxas de mortes femininas (B) por agressão em municípios de linha de fronteira, Brasil, 2000-2015.

Fonte: Brasil, Ministério da Saúde. DATASUS, 2000-2015.

brasileiros. O Arco Central apresentou a maior quantidade de municípios com número elevado de feminicídios, embora no Arco Norte houvesse alguns municípios com taxas elevadas, aumentos abruptos e elevada mortalidade de mulheres indígenas. Na linha de fronteira, ocorreram 181 assassinatos de mulheres indígenas, representando $13 \%$ do total dos homicídios femininos, localizados majoritariamente no Arco Norte, onde municípios de pequeno porte, como Alto Alegre 
(RR), Caracaraí (RR) e Barcelos (AM), apresentaram altas frequências nos últimos anos da série (41,49 e 44 mortes; taxas de 33, 35 e 23 casos por 100 mil mulheres, respectivamente). Nesses três municípios da Amazônia legal, ocorreram 109 mortes de mulheres indígenas, $60 \%$ do total.

O Quadro 2 mostra as variáveis que permaneceram no modelo final: índice de Gini, Arco Central, migração, percentual de população autodeclarada negra e municípios com mais de 20.000 habitantes.

As mortes femininas por agressão estiveram associadas positivamente com o número de migrantes, o tamanho da população e o Arco Central. Viver no território do Arco Central, ter maior quantidade de migrantes e municípios maiores constituíram situações de risco para as mulheres.

Apareceram duas associações paradoxais e negativas: a primeira com o índice de Gini, uma vez que em locais com menor concentração de renda a mortalidade feminina foi maior, a segunda em relação à população negra, pois a mortalidade foi menor nos municípios em que há maior percentual de pessoas autodeclaradas negras. Em relação ao percentual de evangélicos, não houve associação com as mortes femininas por agressão.

\section{Discussão}

Os municípios mais populosos da linha de fronteira foram os que apresentaram maiores taxas de violência letal contra as mulheres. A estratificação dos municípios em com mais e menos de 20.000 habitantes permitiu observar que a violência está relacionada ao tamanho da população e que, nos municípios mais populosos, as mulheres estão em maior risco ${ }^{24,25}$. A explicação para esse padrão pode se dever ao conservadorismo das pequenas cidades, onde o comportamento das pessoas é mais socialmente controlado, as normas de gênero são mais rígidas e as mulheres precisam cumprir estritamente os papeis designados a elas pela cultura, ao contrário das grandes cidades cosmopolitas e binacionais, onde a mobilidade social é intensa, mulheres migrantes estão sem redes de apoio, agudiza-se a exploração sexual e os padrões tradicionais de gênero são flexibilizados ${ }^{25}$.

Mesmo assim, nos últimos anos da série houve municípios pequenos que notificaram elevado número de mortes femininas por agressão. Foram temporalmente concentradas, o que pode indicar a ocorrência de conflitos, como massacres, que envolvem mais de uma mulher, muitas vezes não percebidos como feminicídios. A região Norte, que até 2010 apresentava índices menores de homicídios, à medida em que passou a fazer parte de rotas de tráfico, começou a testemunhar guerras entre facções, mortes de militantes camponeses, de mulheres e de lideranças indígenas ${ }^{26}$.

Trabalhou-se com a população autodeclarada negra, já que em outros trabalhos se observou uma sobremortalidade por homicídios de mulheres racializadas ${ }^{19,26}$. Porém, no presente estudo a associação foi negativa, de modo que nos municípios onde há mais negros houve menos feminicídios, embora no Arco Norte, por sua extensão, dispersão territorial e isolamento dos grupos populacionais, seja possível que nem todas as mortes tenham sido notificadas.

Wanzinack e colaboradores ${ }^{27}$ demonstraram que os homicídios em indígenas no Brasil são subnotificados e que as informações sobre a saúde dessa população são precárias, ao mesmo tempo em que os feminicídios em mulheres indígenas têm sido cada vez mais denunciados no país $^{28}$. Nesta pesquisa, identificou-se que 13\% do total dos homicídios femininos na linha de fronteira foram de mulheres indígenas, o que representa uma sobremortalidade, já que o percentual de população autóctone na região varia de $11 \%$

Quadro 2. Mortes femininas por agressão e variáveis que permaneceram no modelo final, municípios de fronteira, Brasil, 2000-2015.

\begin{tabular}{|l|c|c|c|c|}
\hline \multicolumn{1}{|c|}{ Variáveis } & Coeficiente & Erro padrão & Z valor & p \\
\hline Intercepto & $-8,824$ & 0,175 & $-50,201$ & $<0,0001$ \\
\hline Índice de Gini 2010 & $-2,506$ & 0,202 & $-12,372$ & $<0,0001$ \\
\hline Arco Central & 0,293 & 0,077 & 3,784 & 0,00015 \\
\hline Migração 2010 & 0,000008 & 0,000002 & 5,167 & $<0,0001$ \\
\hline População negra 2010 & $-0,007$ & 0,002 & $-3,452$ & 0,00056 \\
\hline Municípios > 20.000 hab. & 0,169 & 0,078 & 2,154 & 0,03121 \\
\hline
\end{tabular}

Fonte: Dados da pesquisa. 
em Roraima, passando por 4,8\% no Amazonas, a 0,8 em Rondônia ${ }^{29}$. Em três municípios pequenos (Barcelos, Alto Alegre e Caracaraí), as taxas foram próximas de 30 por mil mulheres, o que é considerado muito elevado ${ }^{20}$ e sinaliza para um possível genocídio ou femigenocídio ${ }^{30,31}$, conceito usado pelo direito internacional quando ocorrem ataques generalizados ou sistemáticos contra qualquer população civil, no caso assassinatos de mulheres étnicas, perpetrados com o descaso ou complacência do Estado, configurando um crime de lesa humanidade.

Em regiões de fronteiras, as mulheres enfrentam problemas pelo fato de viverem no contexto de nações que possuem legislações e estruturas governamentais diferentes, aliado ao distanciamento dos centros de poder, à falta de conhecimento sobre direitos e à pobreza. Na fronteira norte do Brasil, a criança, a adolescente e a mulher indígena são as vítimas mais frequentes, e mesmo quando o Estado se faz presente, muitas vezes ocorre revitimização, na medida em que são desconsiderados os laços comunitários, aumentando a vulnerabilidade das pessoas afeta$\operatorname{das}^{32}$.

Além disso, a visibilidade dos feminicídios em indígenas nas estatísticas vitais fica prejudicada, já que as unidades da Federação que compõem a região amazônica apresentam população oriunda de três matrizes principais (negra, indígena e branca), e corriqueiramente não se inclui o elemento indígena na identificação das pessoas. Assim, a ascendência indígena é desconsiderada nos registros de mortalidade, o que explica o aumento das taxas de homicídios em brancos nessa região ${ }^{33}$. Tal cenário se deve ao descaso com essa população, manifesto também na falta de qualidade das informações e nos problemas de preenchimento dos campos de raça/cor nas declarações de óbito, acrescidos pela fragmentação da Secretaria Especial de Saúde Indígena (SESAI), que tem restringido o acesso de informações sobre a população autóctone ${ }^{34}$.

No Brasil, houve um aumento da taxa de homicídios e um processo de interiorização do crime nos últimos anos. Em regiões de fronteira, ocorreu crescimento de homicídios ligados ao narcotráfico, especialmente na rota da cocaína procedente do Peru e da Bolívia. Nesses locais, houve um aumento vertiginoso de violações perpetradas contra as populações indígenas, incluindo ocupação de terras e assassinato de lideranças e mulheres ${ }^{26}$. Esse quadro constitui um dos novos cenários dos feminicídios ${ }^{35}$, nos quais as mulheres, segundo Segato ${ }^{30}$, tornam-se vítimas sacrificiais de grupos criminosos organizados em gangues, milícias e máfias.

Desse modo, as mulheres que ficavam fora dos “ajustes de contas" entre homens, nas novas organizações e redes delitivas que o modelo neoliberal alimenta e subordina ao princípio da rentabilidade, tornaram-se território de vingança e são cada vez mais eliminadas por facções rivais para cobrança de contas ou para mostrar quem detém mais poder ${ }^{35,36}$. Locais onde a violência estrutural entre homens é elevada, regiões de conflitos e guerras podem aumentar exponencialmente a violência dirigida às mulheres, por meio de perseguições, estupros seletivos e mortes ${ }^{19,30}$.

O Arco Central é o que apresenta as maiores taxas de mortes femininas por agressão, incluindo municípios que estão entre os mais violentos do país, como Foz do Iguaçu e Guaíra. Estes locais são considerados pelo discurso da segurança como terra sem lei, ou zona cinza, regiões associadas ao crime transnacional organizado, à presença de máfias e à corrupção de funcionários do Estado, que produz um vazio legal em relação ao controle estatal ${ }^{36}$.

$\mathrm{Na}$ tríplice fronteira Brasil-Argentina-Paraguai, o comércio de drogas e de armas encobre o de pessoas e as fronteiras secas são as principais rotas do tráfico humano. A presença de um lugar sem lei na tríplice fronteira da região mais rica do Brasil indica que a globalização tem contribuído para o enfraquecimento do poder territorial do Estado e a perpetuação das práticas coloniais de poder, amparadas na dominação, na exploração e na violência como estratégias de reprodução do modelo de divisão internacional do trabalho ${ }^{4,37-39}$.

Encontrou-se uma associação entre migração e violências, relação conhecida de longa data mas que se incrementou recentemente pelo processo mundial de feminização $0^{37,40}$. A migração de contingentes de mulheres jovens, procedentes de países periféricos, deve-se à pobreza, à ausência de oportunidades de trabalho, à discriminação de gênero e à instabilidade política, econômica e civil em regiões de conflito. Sem documentos ou com os passaportes retidos, muitas das jovens traficadas se encontram em situação irregular, o que as expõem a redes criminosas que as exploram e as obrigam a trabalhar em condições degradantes, servis ou mesmo de escravidão ${ }^{11,25}$. No Brasil, as mulheres traficadas e vítimas de exploração sexual e prostituição forçada são na maioria adolescentes que circulam dentro do país e em rotas para o exterior, via fronteiras terrestres ${ }^{41,42}$. Enfim, a migração é um processo que impacta a estrutura e a dinâmica demográfica, econômica, 
política, bem como a saúde das populações das regiões e países afetados.

Globalização, fronteiras e territórios de violência suscitam perguntas de como os Estadosnação estão se debruçando, ou não, sobre esses problemas. Há poucos estudos e pesquisas na literatura que abordam a relação entre gênero, fronteiras e assassinatos de mulheres, excetuando-se a produção sobre os feminicídios seriais de Juarez, na fronteira norte do México. Em relação a Juarez, o texto de Rita Segato ${ }^{43}$ desvenda os sinais, a pedagogia da violência inscrita pelas fratrias mafiosas no corpo das vítimas com a cumplicidade silenciosa das autoridades locais. A violência produz uma escritura no corpo das centenas de mulheres violadas, torturadas e mutiladas, divulgando para a sociedade uma mensagem de terror de um segundo Estado.

Ainda sobre os assassinatos ocorridos em Ciudad Juarez, a fronteira e o deserto, locais onde os corpos das mulheres eram descartados em lixões, são descritos como espaços transitórios, onde tudo é efêmero, os valores são flutuantes, as emoções e a empatia estão bloqueadas, as histórias pessoais de nada valem, onde pode eclodir e se naturalizar a banalidade do $\mathrm{mal}^{44}$.

No México, devido à violência estrutural em que o país se encontra imerso, as principais rotas de trânsito são controladas pelo crime organizado e os migrantes que entram nesses territórios estão sujeitos a toda sorte de violências e mesmo à morte ${ }^{45}$. Em Chihuahua e Sonora, na fronteira com os Estados Unidos, as detenções de crianças sem familiares ${ }^{46}$ e de mulheres transgênero ${ }^{47}$ são alguns exemplos da violência sancionada por Estados-nação. Desprotegidas legalmente, essas pessoas sofrem preconceitos, estigmas e discriminação ${ }^{48}$, uma situação que não difere daquela de outros países latino-americanos e de tantos pontos da fronteira brasileira.

\section{Considerações finais}

Esta pesquisa identificou a magnitude dos homicídios de mulheres na linha de fronteira brasileira em uma série histórica de 16 anos. Observou-se uma mortalidade feminina por agressão maior do que a média nacional, associada à migração, a municípios mais populosos e ao Arco Central. Os níveis de mortalidade foram crescentes na série histórica, porém nem todos os 122 municípios apresentam o mesmo perfil, há grande heteroge- neidade entre esses locais, o que indica a necessidade de monitorar de modo particularizado esse evento. Portanto, deve-se atentar para as altas frequências em municípios populosos, sem descuidar das mudanças abruptas em municípios pequenos, sinalizando eventos sentinela, como a entrada do tráfico, conflito de terras ou chacinas.

Em relação às relações paradoxais e inversas que aconteceram com população negra e com o índice de Gini, acreditamos que os óbitos em mulheres racializadas podem ficar invisibilizados, como apontado pelo Atlas da Violência ${ }^{33}$, o que não significa que o racismo e a racialização deixaram de incidir sobre esses eventos violentos. E embora não tenham sido encontradas explicações para as mortes seguirem direção inversa à concentração de renda, por se tratar de um estudo ecológico há a possibilidade de os feminicídios estarem ocorrendo em bairros e regiões mais pobres das cidades.

Uma limitação deste estudo diz respeito aos dados de mortalidade obtidos do SIM que incluem um percentual crescente de mortes violentas atribuídas a causas indefinidas, que podem aumentar as taxas de feminicídios, especialmente em municípios de fronteira, onde a pouca presença do Estado facilita a simulação de um acidente ou suicídio para ocultar um assassinato ${ }^{26}$.

A ausência do Estado de direito e a impunidade estão entre as principais causas da perpetuação da violência de gênero extrema nas Américas ${ }^{48}$, inclusive em seus pontos mais remotos, como as fronteiras. Anzaldua ${ }^{49}$, pensadora feminista, considera a fronteira uma ferida, ou seja, um local onde a violência contra o feminino pode assumir proporções epidêmicas, aguçada pela misoginia, pelo machismo e pela cultura patriarcal. Pode-se pensar ainda na fronteira como um não lugar ${ }^{50}$, um cenário de transitoriedade e de invisibilidade, onde populações originárias, os e as indígenas, camponeses, ribeirinhos, quilombolas, mulheres e crianças - as minorias e os despossuídos - são considerados e tratados como pessoas supérfluas e elimináveis.

Enfim, as fronteiras são locais onde a legitimidade do Estado-nação, forjada no ideário europeu, atinge a sua máxima contradição. O cenário desses territórios propicia a perpetuação da dinâmica da violência por meio da instalação de organizações e redes criminosas que, sob a lógica de extração máxima de lucro, subordinam as mulheres, explorando-as, traficando e eliminando-as quando não lhes servem mais. 


\section{Colaboradores}

SN Meneghel coordenou a pesquisa e elaborou o artigo. IM Danilevicz realizou a análise estatística. M Polidoro elaborou os mapas e a discussão sobre fronteiras. LM Plentz e BP Meneghetti organizaram os bancos de dados.

\section{Financiamento}

CNPq PQ 12-2016. "Feminicídios em regiões de fronteira” (442883/2016-1). Edital MCT/CNPq/ SPM. Relações de gênero, mulheres e feminismos. Edital 20/2010. "Feminicídios e assassinatos pautados em gênero no Rio Grande do Sul" (401870/2010-3).

\section{Referências}

1. Silva CAF. Fronteira agrícola capitalista e ordenamento territorial. In: Santos M, Becker BK. Território, territórios: ensaios sobre ordenamento territorial. $2^{\mathrm{a}}$. ed. Rio de Janeiro: SDP \& A; 2006. p.283-314.

2. Martins JS. Fronteira: a degradação do outro nos confins do humano. São Paulo: Contexto; 2009.

3. López MV, Pastor MP, Giraldo CA, García HI. Delimitación de fronteras como estrategia de control social: el caso de la violencia homicida en Medellín, Colombia. Salud Colectiva 2014; 10(3):397-406.

4. Webb D, Vega LR. Security and well-being in the Triple Frontier Area of Latin America: community awareness of child trafficking, the smuggling of persons and sex tourism. In: Webb D, Wills-Herrera E, organizadores. Subjective well-being and security. Social indicators research series. Dordrecht: Springer; 2012. p. 291-323.

5. Dusse E. Europa, modernidad y eurocentrismo. In: Lander E., organizador. La colonialidad del saber: eurocentrismo y ciencias sociales, perspectivas latino-americanas. Buenos Aires: Clacso; 2000. p. 24-32.

6. Quijano A. Colonialidade, poder, globalização e democracia. Revista Novos Rumos 2002; 17(37):1-25.

7. Machado LO, Novaes AR, Monteiro LR. Building walls, breaking barriers: Territory, integration and the rule of law in frontier zones. Journal of Borderlands Studies 2009; 24(3):97-114.

8. Ilanzo MPQ, Urbano OMC, Delgado MC, Ramirez NP, Mendoza GMP, Garcia AEO. Violencia extrema contra la mujer y feminicidio en el Perú. Rev Cubana Salud Publica 2018; 44(2):278-294.

9. Leal ML, Leal MFP. Pesquisa sobre tráfico de mulheres, crianças e adolescentes para fins de exploração sexual comercial no Brasil. Brasília: Centro de Referência, Estudos e Ações sobre Crianças e Adolescentes (CECRIA); 2002.

10. Colares M. Diagnóstico sobre o tráfico de seres humanos: São Paulo, Rio de Janeiro, Goiás e Ceará. Brasília: Ministério da Justiça; 2004.

11. Brasil. Secretaria Nacional de Justiça (SNJ). Pesquisa ENAFRON diagnóstico sobre tráfico de pessoas nas áreas de fronteira. Brasília: SNJ, 2012.

12. Silva MA. Vicissitudes da Saúde no contexto da migração, do tráfico, da exploração sexual e do trabalho degradante In: Brasil. Saúde, migração, tráfico e violência contra mulheres: o que o SUS precisa saber. Brasília: Ministério da Saúde (MS); 2013. p. 27-59.

13. Russel D, Caputti J. Femicide: the politics of women killing. New York: Twayne Publisher; 1992.

14. Widmer M, Pavesi I. A gendered analysis of violent deaths. Small Arms Survey Research Notes 2016; 63:18. [cited 2021 Dec 8]. Available from: http://www. smallarmssurvey.org/fileadmin/docs/H-Research_ Notes/SAS-Research-Note-63.pdf

15. Nogueira VD, Xavier-Gomes LM, Barbosa TLA. Mortalidade por homicídios em linha de fronteira no Paraná, Brasil. Cien Saude Colet 2020; 25(8):3107-3118.

16. Salla F, Alvarez MC, Oi H. Homicídios na faixa de fronteira do Brasil, 2000-2007. (Relatório de Pesquisa do Projeto Violência e Fronteiras - FAPESP/CNPq). São Paulo: Núcleo de Estudos da Violência da USP (NEV/ USP); 2011. 
17. Brasil. Ministério da Justiça (MJ). Segurança, Justiça e Cidadania. Fronteiras, armas e drogas. Brasília: Secretaria Nacional de Segurança Pública (SENASP); 2014, ano 4, n.8.

18. Ratton JL. Mulheres, violência e percepção da violência em Pernambuco. In Sento-Sé JT, organizador. Segurança pública: outros olhares, novas possibilidades. Brasília: Presidência da República/Secretaria Especial de Políticas para Mulheres; 2009.

19. Meneghel SN, Hirakata VN. Femicídios: assassinatos de mulheres no Brasil. Rev Saude Publica 2011; 45(3):564-574.

20. Nowak M. Femicide: a global problem. Small Arms Survey Research Notes 2012; 14:1-4. [cited 2021 Dec 8]. Available from: https://www.smallarmssurvey.org/ resource/femicide-global-problem-research-note-14

21. Brasil. Ministério da Integração Nacional (MIN). Comissão permanente para o desenvolvimento e integracão da faixa de fronteira. Brasília: MIN; 2012.

22. Wailselfisz JJ. O mapa da violência 2015. Homicídios de mulheres no Brasil. Rio de Janeiro: CEBELA, FLACSO; 2015.

23. Nelder JÁ, Wedderburn RWM. Generalized Linear Models. Journal of the Royal Statistical Society (Series A) 1972; 135(3):370-384.

24. Grana SI. Sociostructural considerations of domestic femicide. Journal of Family Violence 2001; 12(4):421435.

25. Meneghel SN, Rosa BAR, Ceccon RF, Hirakata VN, Danilevicz IM. Feminicídios: estudo em capitais e municípios brasileiros de grande porte populacional. Cienc Saude Colet 2017 22(9):2963-2970.

26. Cerqueira D, Lima RS, Bueno S, Alves PP, Reis M, Cypriano O, Armstrong K. Atlas da violência. Retratos dos municípios brasileiros. Brasília: Ipea; 2019.

27. Wanzinack C, Signorelli MC, Shimakura S, Pereira PPG, Polidoro M, Oliveira LB, Reis, C. Indigenous homicide in Brazil: geospatial mapping and secondary data analysis (2010 to 2014). Cien Saude Colet 2019; 24(7):2637-2648.

28. Feminicídio. Relatório estatístico do Poder Judiciário. Campo Grande: Tribunal de Justiça do Mato Grosso do Sul, Coordenadoria estadual da Mulher; 2019.

29. Instituto Brasileiro de Geografia e Estatística (IBGE). Os indígenas no censo demográfico 2010. Primeiras considerações com base no quesito raça/cor. Rio de Janeiro: IBGE; 2012.

30. Segato R. La guerra contra las mujeres. Madrid: Traficante de Sueños; 2016.

31. Malheiro L. Femigenocídio em nome da guerra às drogas e o projeto politico feminista antiproibicionista [Internet]; 2019. [acessado $2021 \mathrm{dez} 8$ 8]. Disponível em: https://usinadevalores.org.br/femigenocidio-em-nome-da-guerra-as-drogas-e-o-projeto-politico-feminista-antiproibicionista/

32. Prado D, Sanematsu M, organizadores. Feminicídio: invisibilidade mata. Fundação Rosa Luxemburgo, Instituto Patricia Galvão; 2017.
33. Cerqueira D, Bueno S, Alves PP, Lima RS, Silva ERA, Ferreira H, Pimentel A, Barros B, Marques D, Pacheco D, Lins GOA, Lino IR, Sobral I, Figueiredo I, Martins J, Armstrong K, Figueiredo TS. Atlas da violência. Brasília: Ipea; 2020.

34. Polidoro M, Mendonça F, Meneghel SN, Goncalves, M, Alves-Britto A, Bairros F, Canavese D. Territories under siege: risks of the decimation of Indigenous and Quilombolas peoples in the context of COVID-19 in South Brazil. J Racial Ethn Health Disparities 2020; Online first: 1-11.

35. Carcedo A. No olvidamos ni aceptamos: Femicidio en Centroamérica 2000-2006. San José: Associación Centro Feminista de Información y Acción (CEFEMINA); 2010.

36. Meneghel SN, Portella AP. Feminicídios: conceitos, tipos e cenários. Cien Saude Colet 2017; 22(9):30773086.

37. Montenegro S. La Triple Frontera entre Argentina, Brasil y Paraguay. In: Carrión F, Llugsha V, organizadores. Fronteras: rupturas y convergencias. Quito: FLACSO; 2013. p. 241-254.

38. Sverdlick AR. Terrorists and organized crime entrepreneurs in the "triple frontier" among Argentina, Brazil, and Paraguay. Trends Organ Crim 2005 9(1):84-93.

39. Carvalho SSG. Tráfico internacional de mulheres para fins de exploração sexual na tríplice fronteira [dissertação]. São Paulo: Universidade Presbiteriana Mackenzie; 2017.

40. Nudelman A, Boira S, Isomaia T, Balica E, Tabaqua S. "Hearing their voices": exploring femicide among migrants and culture minorities. Qualitative Sociology Review 2017; 13(3):50-68.

41. Pimentel GA, Oliveira RS. Tráfico de mulheres para fins de exploração sexual comercial na fronteira Brasil-Venezuela: o caso da Br-174. In: Grupo de Pesquisa sobre Violência, Exploração Sexual e Tráfico de Mulheres, Crianças e Adolescentes, organizador. Tráfico de pessoas e violência sexual. Brasília: VIOLES/SER/ Universidade de Brasília; 2007. p. 59-74

42. Organização Internacional do Trabalho (OIT). Tráfico de pessoas para fins de exploração sexual. Brasília: Secretaria Internacional do Trabalho; 2006.

43. Segato LR. La escritura en el cuerpo de las mujeres asesinadas en Ciudad Juárez. Buenos Aires: Tinta Limón 2013.

44. Bernal, RP, Pérez MLB, Stajnfeld S. Desierto, capitalism y valores machistas en "la parte de los crimines" de 2666. Cuadernos de CILHA 2015; 16(22):1-20.

45. Infante C, Silvan R, Caballero M, Campero L. Sexualidad del migrante: experiencias y derechos sexuales de centroamericanos en tránsito a los Estados Unidos. Salud Publica Mex 2013; 55(Supl. 1):s58-s64.

46. Danticat E. We must not forget detained migrant children. The New Yorker 2018; 26 Jun. [cited 2021 Dec 8] Available from: https://www.newyorker.com/news/ news-desk/we-must-not-forget-detained-migrantchildren 
47. Oztaskin M. The harrowing, two-year detention on a transgender asylum seeker. The New Yorker 2019, 31 Oct. [cited 2021 Dec 8]. Available from: https://www. newyorker.com/news/dispatch/the-harrowing-two -year-detention-of-a-transgender-asylum-seeker

48. Saccomano C. El feminicídio em América Latina: vacio legal o déficit del estado de derecho? Revista CIDOB d'Afers Internacionals 2017; 117:51-78.

49. Anzaldua G. Borderlands, the new mestiza. La Frontera. 4th edition. San Francisco: Aut Luke Books,; 2012.

50. Augé M. Não lugares. Uma introdução a uma antropologia da super modernidade. Campinas: Papirus Editora; 2017.

Artigo apresentado em 22/07/2020

Aprovado em 04/12/2020

Versão final apresentada em 06/12/2020

Editores-chefes: Romeu Gomes, Antônio Augusto Moura da Silva 